\title{
Architecture In-Play, Future Challenges
}

\author{
Alexandra Paio ${ }^{\text {(DD }}$ - Filipa Osório² ${ }^{2}$ \\ Sancho Moura Oliveira ${ }^{3}$ (D) Graziano Mario Valenti ${ }^{4}$. \\ Nuno Guimarães ${ }^{5}$ (i)
}

\begin{abstract}
This paper discusses an emerging field of research in architecture, kinetic design. This approach has been used in different ways through history, but the technological advances of the "Third Industrial Revolution" offer new perspectives on this topic, along with various design innovations. To face this demand, architects must develop new strategies rooted in performance, connectivity and control, and process them to support and inform design. In order to explore these challenges, a group of researchers organized a summer school in 2016. The partnership between ISCTE-IUL and Sapienza University of Rome emerged as an opportunity to join an international community to present recent research, teaching or practice related to
\end{abstract}

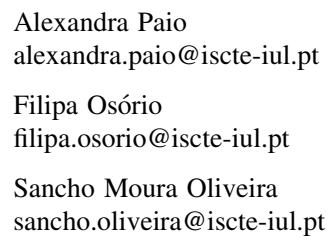

1 ISCTE-Instituto Universitário de Lisboa, ISTAR-IUL, DINÂMIA'CET and Vitruvius FabLabIUL, Avenida das Forças Armadas, 1649-026 Lisbon, Portugal

2 ISCTE-Instituto Universitário de Lisboa, ISTAR-IUL and Vitruvius FabLab-IUL, Avenida das Forças Armadas, 1649-026 Lisbon, Portugal

3 ISCTE-Instituto Universitário de Lisboa, Instituto de Telecomunicações and Vitruvius FabLabIUL, Avenida das Forças Armadas, 1649-026 Lisbon, Portugal

4 Sapienza University of Rome, Via San Leo, 18, 0013 Rome, Italy

5 ISCTE-Instituto Universitário de Lisboa, ISTAR-IUL, Avenida das Forças Armadas, 1649-026 Lisbon, Portugal 
architecture, technology, computation, mathematics and geometry. In addition, an experimental learning-by-doing design studio was developed, which allowed for testing a digital workflow to create foldable surfaces based on rigid origami geometry. The major objective of these events, which is summarised in this paper, is to contribute to the debate around digitally-driven kinetic architecture.

Keywords Kinetic architecture - Computational design · Rigid origami geometries · Parametric design · Foldable structures - Digital fabrication

\section{Introduction}

In recent years, digital innovations have become especially tangible, not only because of the availability of new technologies, but also for the high-level and widespread computer literacy that has become common. This knowledge has also affected designers, who have begun to conceive a range of changing, versatile and effective artefacts. In the modern world, technologies weave themselves into the fabric of everyday life until they become invisible (Weiser 1991). Computation is now everywhere and is directly relevant to architectural practice today, where ubiquitous computing is giving architecture new functions.

The shift from mechanical to digital processes also offers new challenges to design research in architecture. Researchers are thinking in terms of customization and adaptability instead of standardization and rigidity. Design processes are no longer seen as cyclical processes or assembly lines, but instead as networks and systems. Spaces are designed based on complex geometry, and fabricated by digital models (Peters and Peters 2013). Furthermore, information technology is being transferred from the world of digital models to the reality of an interactive architecture (Saggio 2013). Knowledge about designed artefacts can be encoded in digital data pertaining not just to the geometry of a design, but also to its physical structural logic or to embedding behaviours into buildings. Negroponte (1995) introduced the concept of bits and atoms, arguing that atoms make up physical, tangible objects and our digital models inhabit the space of bits as information in the computer that is used to design. Consequently, architecture has witnessed a growing volume of experimentation with ways of using digitally managed information to rethink how buildings are designed.

\section{Background to Kinetic Architecture}

The foundations for much of this work can be traced to the second half of the twentieth century, and the work of cyberneticists on systems adapting to continuous feedback from the environment. Norbert Wiener's (1948) book, where the first public usage of the term "cybernetics" to refer to self-regulating mechanisms is seen, is an example of this. From this foundation, Gordon Pask (1969) and Cedric Price made advancements toward understanding and identifying the field of kinetic architecture, and in the 1960s Archigram's vision of indeterminate architecture 
contributed to the field (Sadler 2005). At the start of the next decade, Zuk and Clark (1970) attempted to introduce physicality to earlier theoretical propositions for kinetic architecture. They defined "kinetic" as a form that could be inherently displaceable, deformable, expandable or capable of movement (Zuk and Clark 1970). Eastman (1971) envisioned spaces and users as feedback systems that would allow architecture to self-adjust to fit the needs of users, and Frazer (1995) continued the cybernetician's work. This emerging field began to transform places into intelligent environments, creating spaces that transport computation into the physical world. Since then, numerous architecture schools have incorporated these kinetic design approaches in their advanced studies programs (Fox and $\mathrm{Hu} 2005$ ).

Kronenberg et al. (2003), defined kinetic architecture as buildings or building components with changeable mobility, location and geometry, and Fox and Kemp (2009) describe it as producing transformable artefacts which dynamically occupy predefined physical space, or moving artefacts that can share a common physical space to create flexible and adaptable spatial configurations. The concept can be understood as the application of the basic paradigm which is at the heart of digital technology: input $\rightarrow$ processing $\rightarrow$ output. Information, which comes mostly from environmental sensors, is appropriately processed to control actuators, which intervene on the architectural form by modifying it.

The "Third Industrial Revolution", which has recently occurred, introduced technological and conceptual advances into fields such as artificial intelligence, robotics and materials science. These advances have enabled these early visionary ideas from architecture to not only be realised physically, but also to be taken in important new directions (Rifkin 2011). Kinetic architecture incorporating structural movement, and responsive or interactive architecture incorporating communication and real-time feedback between structure and user/environment, have been demonstrated in recent prototype projects from dECOi, ORAMBRA, Vershure and Hoberman Associates Inc. (Bier and Knight 2010; Goulthorpe 2008; Kolarevic and Parlac 2015).

Rigid-foldable systems based on origami geometry have been explored in architectural research studies in the digital age (El-Zanfaly 2011; Rivas-Adrover 2015). Folding is a powerful technique that turns a flat surface into a threedimensional one, to create self-supporting structures. Greg Lynn (1993: 8) argues that "if there is a single effect produced in the architecture of folding, it will be the ability to integrate unrelated elements within a new continuous mixture". Folding as a material technique is a generative design tool that has gained currency in digital fabrication processes. For Iwamoto (2009: 62), "folding expands the threedimensional vocabulary of surface by naturally producing deformation and inflection. Digital tools enable subtle and complex geometric modulations, affording the ability to both incorporate and smooth over difference". The modelling, parametric simulation and manufacturing of rigid-foldable systems includes deployable principles inspired by paper pleat techniques from Miura-Ori or Ron Resch patterns (Demaine et al. 2011). Many design approaches of this type have been proposed, but they are limited to a drawing or simulation, without taking into account technological and mechanical issues (Casale and Valenti 2012; Schenk and Guest 2011). Rigid origami folding simulations are already found in the work of 
Lang (2010) and Tachi (2011). Daniel Piker has also produced several origami folding definitions in Grasshopper3D. To take advantage of these developments, it is important to create digital workflows that integrate both geometric and technological features (Marbel 2012). The variables are unlimited, and involve the concerted efforts of different disciplines in the design of kinetic rigid-foldable architectural systems (Megahed 2017).

In order to investigate these processes and their contributions to architecture, teams from Sapienza, Rome and ISCTE-IUL, Lisbon, got together to host a conference and a design studio where this new paradigm in architecture could be experienced. The main goal of the design studios was to experiment with a digital workflow to support the kinetic potential of origami surfaces simulating different geometries, and their inherent movements, rigid materials and digital fabrication techniques. A team composed of architects, computer scientists and electrical engineers defined a programme to provide participants with the theoretical background and instrumental skills.

\section{The Architecture In-Play Conference}

The conference, which was held at ISCTE-IUL from July 11 to 23, 2016 (Fig. 1), received contributions from fifteen countries and was structured in four thematic sessions: (1) interactive architecture-adaptive world; (2) interactive architecturelaboratory; (3) computational design; (4) origami geometry and mathematics. Each session started with a lecture from a keynote speaker, followed by paper presentations.

Michael Fox's lecture "Catalyst Design" focused on his books Interactive Architecture (Fox and Kemp 2009) and Interactive Architecture: Adaptive World (2016b). These books constitute a state-of-the-art review of architecture and its relationship with digital technologies. Fox states that interactive architectural projects are increasingly being built, and are getting bigger in scale and better in material performance, connectivity and control. Computation is becoming invisible in our buildings and environments, as ubiquitous computing is becoming the standard in architecture. He argues that interactive design is getting more accessible to architects due to the technological developments that make them cheaper and the change in many architecture schools that now include courses in robotic prototyping and interaction. Furthermore, architects are not expected to create their "interactive projects" alone, but rather to have enough knowledge to have the freedom to create a design and to understand what can be done and how. According to Fox "the requisite technologies are simple enough to enable designers who are not experts in computer science to prototype their ideas in an affordable way and communicate their design intent" (Fox 2016a: 2).

Interactive design is evolving rapidly in a world where everything is connected to the Internet of Things, and this is changing the way we live our lives, the interactions we have with other people and the design of objects, buildings and cities. For Fox (2016a: 4), “[i]nteractions are no longer limited to those of people interacting with an object, environment or building, but can now be carried out as 


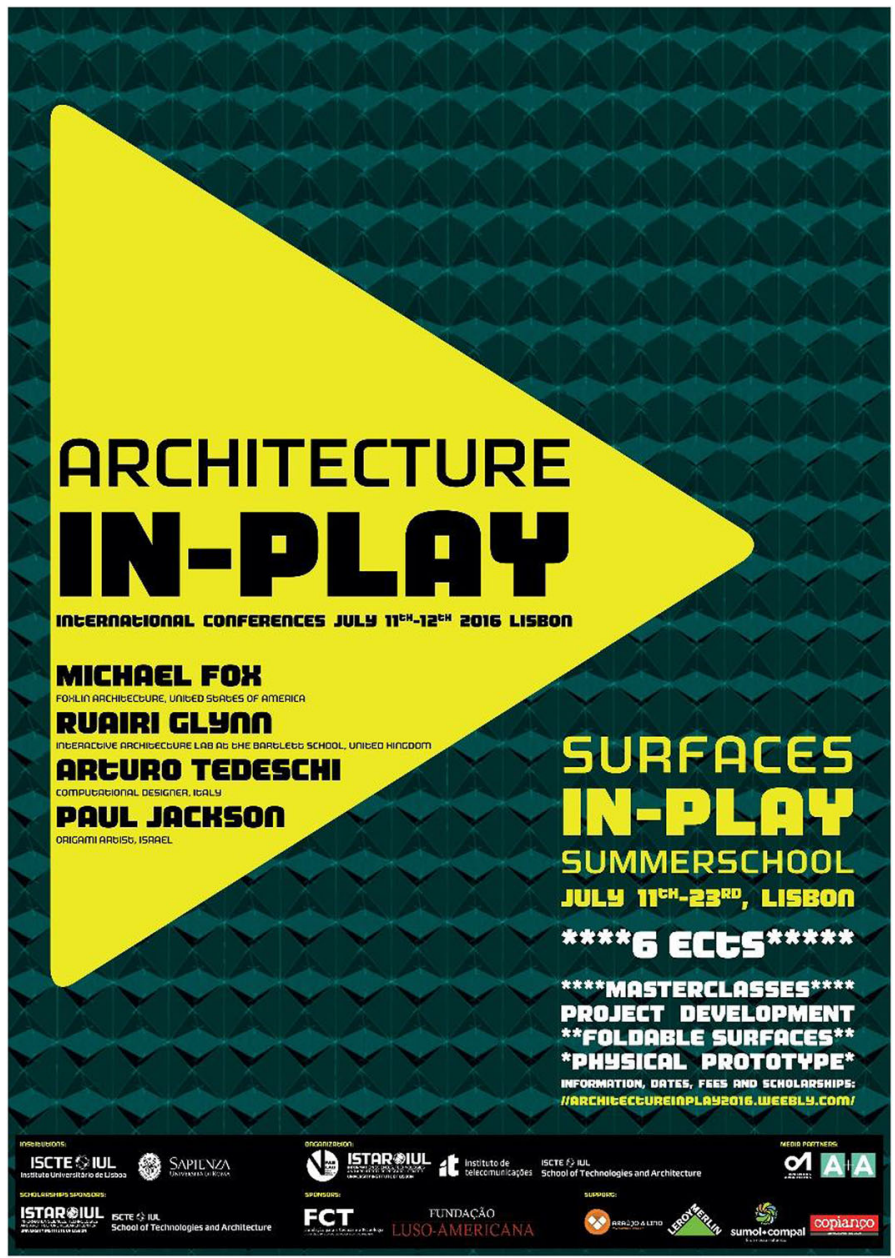

Fig. 1 In-Play's conference and summer school poster. Source: Filipa Osório

part of a larger ecosystem of connected objects, environments, and buildings that autonomously interact with each other". These interactions occur through tangible user interfaces (instead of graphical interfaces), which create a sensorial richness to the relationship of the user with the constructed environment. In addition, he says, "tangible interaction encompasses user interfaces and interaction approaches that emphasize the sensory appeal and materiality of the interface, the physical embodiment of data, whole-body interaction, and the embedding of the interface and the users' interaction in real spaces and contexts" (Fox 2016a: 5). Fox maintains that tangible interaction and connection capabilities have opened the door to a multitude of possibilities, not only at the scale of the building but also to the scale of the city and beyond (Daly 2011: 3). Fox finishes his contribution to the 
conference with a reflection on the ways that these new paradigms have affected the role of the architect. "Within a profession recently dominated by a discourse of style, we have begun to detect a shift away from questions of representation and images toward processes and behaviours" (Fox 2016a: 5).

In his talk, Ruairi Glynn from the Interactive Architecture Lab, Bartlett School, in London, addressed the role of technologies and cybernetics in life. His talk started by analysing, throughout history, the ways Man uses machines to mimic life. Glynn (2016: 60) states that "Man has mimicked the forms and behaviours of life to better understand them". He makes reference to DNA research and replicability, and describes the evolution of mechanical automata mainly through the inventions of Tommaso Francini (1571-1651) and Jacques Vaucanson (1709-1782) whose automata and inventions were "the genesis of programmable machines that were to lead to the age of computing" (Glynn 2016: 63).

These experiments, he argues, are “useful to reflect on how today's concepts of machine, autonomy, adaption, emergence and complexity [are] formed from the conflict between a human tendency towards vitalism and modern science's tendency towards reductive mechanism" (Glynn 2016: 61). Glynn states that after Luigi Aloisio Galvani (1737-1798) discovered the relationship between electricity and muscle movement in 1780, "the making of lifelike machines would move from pneumatic and hydraulic mechanisms towards electromechanical brains and servomechanisms in the perennial search for ever more life-like forms of behaviour" (Glynn 2016: 63). He then examined examples of life imitating automatons and cybernetic machines, including inventions like Electro-Mechanical Animals (Machina Speculatrix) (Walter 1950) from neuroscientist W. Grey Walter (1910-1977). These are some of the earliest autonomous robots built which, despite their very simple nervous system, perform a variety of complex patterns of movement.

Cybernetic machines often have unexpected behaviours that can be observed when the environment changes. These emergent behaviours can be caused by numerous reasons that give stimuli to the sensors that were not prefigured by the creator of the machines, hence generating unanticipated behaviours. Glynn argues that emergent or unexpected behaviours must be part of the design, and there must be space to let this happen. There must also be a capacity for observation of the object in a certain habitat that allows conclusions to be drawn and deeper knowledge of the created object and its relationship with its environment developed. He suggests that designers should use cybernetic principles, wherein the behaviour of an agent-system is coupled to its environment, and that architecture should use cybernetics' theoretical framework for studying behaviour. Glynn (2016: 68) declares, "[t]he inherent unpredictability and the emergent novelty to be found in designing behaviour in concert with its environment has important implications for design that are under-appreciated in Architecture but appear essential to understanding the mechanisms and possibilities of a future living architecture".

The computational designer Arturo Tedeschi (2011, 2014), who has authored several books of parametric architectural strategies using grasshopper, presented 'Hyper-meritocracy and architecture'. This lecture focused on the change to the architect's role in the context of Europe's current economic status and the impact 
that it has had on architecture firms and particularly on young (under 40 year old) professionals. The answer, according to this lecture, and to Cowen's book (2013), to surviving is to embrace the new technologies and use them in the architectural design process. The survivors will be selected through a process of "hypermeritocracy" based on measurable skills. Tedeschi (2016: 123) supports the theory of "social Darwinism, where the survivors will be those whose skills complement those of the new technologies". He argues that

technology [...], in terms of new skills and techniques, is the answer by which tomorrow's architecture will be designed and constructed. From parametric design and AAD (algorithms-aided design), to automated manufacturing, to 'big data' analytics and virtual/augmented reality, computation will be increasingly important as a tool in our environment. Architects should see computation as a technology leading to a crucial shift in industry and society and, more radically, one that can change the way they work (Tedeschi 2016:123).

For Tedeschi, "architect 3.0" is arising. This paradigm shift in the profession asks for a deeper control and understanding of datasets, and strategies to collect and process data in order to face the complexity of the real world and incorporate that complexity into design. In other words, "from running-shoes to high-rise buildings or bridges, data is crucial to develop ambitious projects, not as a representation of complexity but as the solution for complexity" (Tedeschi 2016: 123). This change in the architects' role can also be observed in European universities and their stricter relationship with architectural practices. Universities are increasingly supporting interdisciplinary research and changing the way "architecture is taught and academic programmes are established and delivered" (Tedeschi 2016: 124). In addition to "classical knowledge", students are also taught logical thinking, data management and interpretation or coding. Tedeschi concluded by saying "the main goal is to move away from the aesthetic-orientated approach to join a data-driven process that can lead the new architect to control all the phases of a design project, from the early design stage to the building site" (Tedeschi 2016: 125).

The final lecture of the conference was given by the origami artist Paul Jackson whose most well-known book is Folding Techniques for Designers (2011). Jackson's lecture "Folding as a language of design" focused on the utilization of "folding" as a language of design in architecture. Jackson argues that this technique is becoming increasingly used by designers of all disciplines and on every kind of product (clothing, lighting, architecture, jewellery). Folding is a way of thinking, conceptualizing and living. For him "folding offers a unique language of design, in which, in its purest form of expression, an object is made from one piece of sheet material. The forms and surfaces possible from this transformative method of manufacture are predominantly elegant, economical and necessarily rational" (Jackson 2016: 187).

Jackson's lecture set out to classify folding, noting that the folding of lines is a one-dimensional process, like the use of linear materials to knit or weave. Twodimensional folding is the most common of the forms of folding, popularised by the art of origami. It is the one that pleats planar materials to create two or three- 
dimensional objects. Three-dimensional folding is the folding of volumes, wherein a solid mass of material is manipulated. He concludes that folding is a powerful tool and a language increasingly utilized by every field of design. For Jackson, "what may initially have seemed to be a minor folk craft (origami) is rapidly evolving to one of the most powerful and creative design languages of our time" (Jackson 2016:194).

Following the keynotes, twenty-eight presentations provided an opportunity to present the most recent works in research, teaching or practice related to: interdisciplinary use of interactive architecture; physical computing approaches; digital fabrication techniques; behaviour based robotics; parametric design tools; modelling and simulation systems; augmented/virtual reality experiences; multimodal interactions; material-computation; bio-inspiration emergent systems; game design environments; origami tessellations and folding techniques; and origami geometrical proprieties.

\section{Surfaces In-Play Summer School Design Studio}

The learning-by-doing experimental design studio acknowledged the complex and interconnected global challenges relating architectural practice to kinetic design strategies. The role of the architect becomes broader in this model: to design a kinetic structure it is necessary to manage information-geometric, structural, kinetic and mechanical - and integrate everything in the final design. Moloney (2011: 9) states "the outcome of kinetic design is not a singular form but a process from which a range of forms manifest over time".

In this context, teams from La Sapienza and ISCTE-IUL tested a digital workflow in a real scenario that would ultimately lead to the creation of a rigid origami foldable surface cover prototype. The scope was to establish inclusive strategies that linked students, researchers, scholars and practitioners with different levels of expertise, and increase their ability to deal with the emerging computational design workflows.

The design studio's overall process was based on a series of five master classes on the following themes: (1) Mechanics and Electricity; (2) Arduino Programming and Interaction; (3) Paper Origami Geometry; (4) Grasshopper, Weaverbird and Kangaroo; and (5) Digital fabrication and assembly.

The main objective of the Mechanics and Electricity theme was to give participants a general overview of how to build systems that are able to act on an origami surface by changing its shape. Several examples of mechanical machines were shown to motivate and introduce the basic mechanical mechanisms that allow the control of how motion propagates through the elements of the structure. The second part of this theme was dedicated to the control of the actuators presented in the first part. In the final part of the master class, participants were introduced to microcontrollers and then to the Arduino Programming and Interaction theme. A brief introduction to the programming environment and the programming language was given. Participants then tested some simple examples and finally a program to 
control the surface was designed by all participants and each team implemented it on their controller.

The third master class theme was dedicated to Paper Origami Geometry. The design of a responsive form, which mutates and aspires to the complexity of reaction and, therefore, of communication-interaction with the user, is easily pursued if it is based on an in-depth knowledge of geometry (Casale et al. 2016). In particular, it is necessary to know the information that generalizes the genesis of the forms and defines their topological continuity and discontinuities, so that they can dynamically change the appearance in the space. During this master class, participants were introduced to the Huzita-Hatori Axioms (Lang 2010; Osório et al. 2017 b, c) and tested on paper Miura and Yoshimura origami tessellations, as well as a variety of patterns included in Jackson (2011). This allowed participants to understand the kinematics of each surface, the possible kinds of movement and the structural capacity gained by paper due to its folding. The conclusions from this master class guided the design of the pattern and movement adopted by each group of participants.

The participants were then introduced to digital simulation using Grasshopper, Weaverbird and Kangaroo. Generating the surface's folding process in space is possible by geometrically controlling the basic constituent entities of the "articulated surfaces": the surface pattern, the line/hinge between the faces, and the point/vertex where the hinges meet. As an example, consider a simple flat square shape divided by two rectangular triangles constructed on the diagonals. The design of the movement considers that the two triangular surfaces approach one another by keeping themselves flat, while the remaining surface of the square becomes a cone. Both solutions have been solved with the generative tools (Valenti et al. 2016). The geometric solution first identifies the basic curve of a hypothetical cone in which the flat surface can be transformed (Fig. 2a, b), then constructs the conical surface between the curve and the vertex in common with the two triangles (Fig. 2c), and finally cuts the cone with three geodetic curves, so as to obtain a form with the same extension as the original surface (Fig. 2d, e).

The analytic solution, instead, first divides the main part of the pattern into $n$ flat elements (slice) (Fig. 3); then defines hinges between the elements and establishes behaviour relations among them. For example, the hinges of the elements that will become a conical surface rotate simultaneously with the same angle. The interaction with the surface occurs by setting the closing angle between the two triangles: the algorithm processes the system data to find a configuration compatible with the shapes and the set of constraints. In this master class, the participants developed the 3D modelling for prototyping this form at the end of the design studio.

The final master class, with the theme Digital Fabrication and Assembly, gave participants an overview of the new challenges of the twenty-first century digital revolution (Kolarevic 2003). The advantages and disadvantages of the Computer Aided Manufacturing technologies were discussed within the context of customized solutions. The participants used Vitruvius FabLab at ISCTE-IUL, including all its machines (CNC milling, laser cutter, and 3D printers). All groups had a squared plywood board $(1 \times 1 \mathrm{~m})$ that would be the base for the suspended origami surface, and would also hold and hide the linear actuator and all of the mechanic system. The 


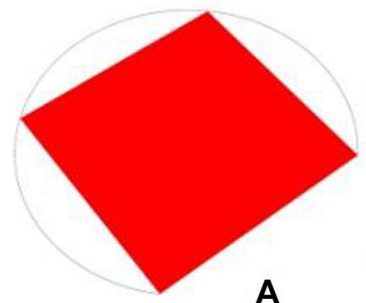

A
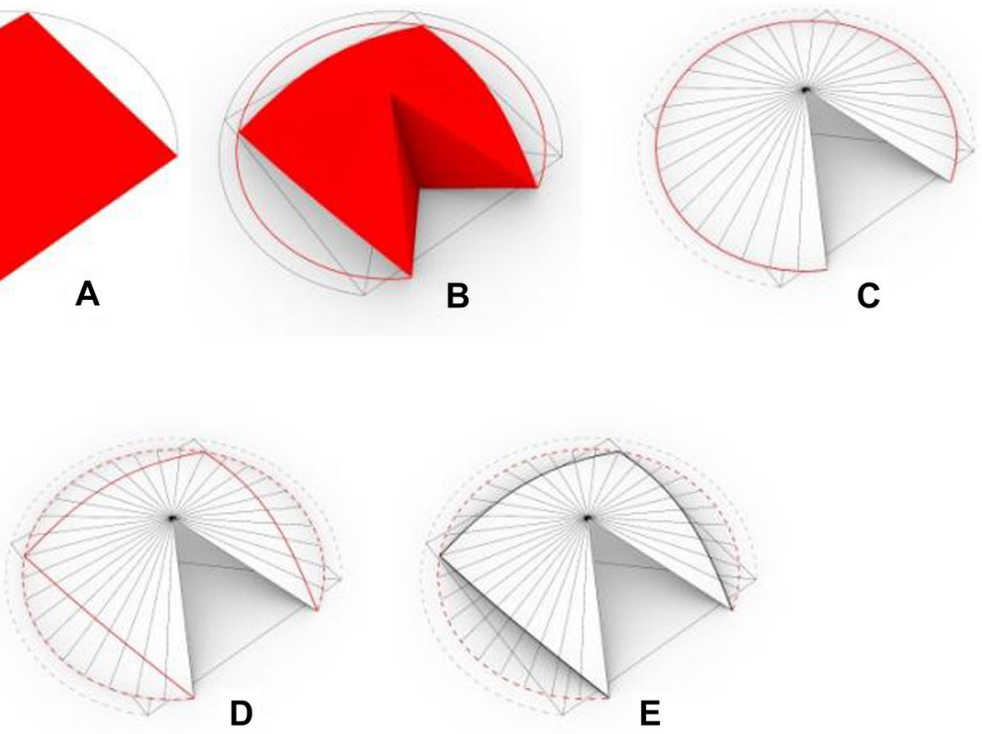

Fig. 2 Geometric solution. Source: Graziano Mario Valenti
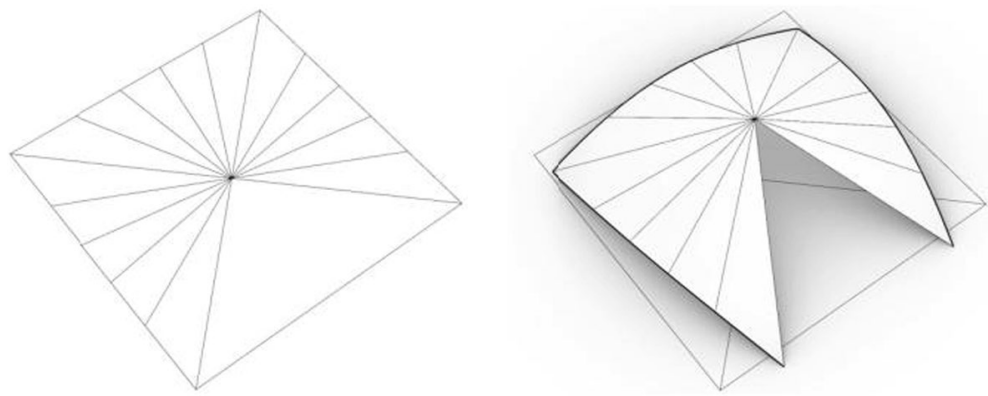

Fig. 3 Analytic solution. Source: Graziano Mario Valenti

experiment allowed for the testing of different origami geometries and inherent movements, rigid materials and digital fabrication methods, 3D parametric visual programming simulation and mechanical structure.

\section{Summer School Outcomes}

The participants' final outcomes demonstrate the skills developed through the production of a rich diversity of rigid origami foldable surface cover prototypes and through testing the proposed digital workflow. The design studio gave an excellent opportunity to discuss different issues in architecture and future challenges. The results of the tasks carried out were posted on an online public platform (http:// architectureinplay2016.weebly.com/). The five prototypes (Fig. 4) were conceived 
by ten participants (PhD students, architecture students, architecture teachers) from six countries (Osório et al. 2017a). Due to space limitations, we only describe prototype A (PA) and C (PC).

PA was formed by four symmetrical modules representing four birds that opened and closed their wings in a diagonal movement set with vertical and horizontal moving points of the surfaces (Fig. 5). The objective was to use linear movement only. Group A used polypropylene and produced the creases directly on the material with the laser cutter. For the kinetic system, the group used one motor actuator SuperJack $12^{\prime \prime}$. The prototype used rails on the plywood base for the moving pieces, like a cross, and had four voids behind the birds where the beak of each would always be in touch with the base. The force of one linear motor made all the lines of movement work in a perfectly synchronised way, and therefore all the birds moved at the same time in tri-directional symmetric ways. PA used the distance sensors so their structures moved every time a person, or an object, moved in the range of the sensor. The values of the sensors would be read by the arduino that would then make the motor work inside a pre-programmed range that fitted the surface's purpose.

PC employed a radial pattern shell surface. This used the $3 \mathrm{~mm}$ plywood and encountered a problem that did not exist on the other prototypes: how to make a surface with thickness fold. To solve that problem, each face was cut individually at the laser cutter and then stitched to the adjacent faces in a way that only allowed the faces to fold in one way, defining in this way the mountain and valley folds. Group $\mathrm{C}$ did not use the motor; the movement was manually achieved to open or close the two module surface (Fig. 6). PC used the upper and lower parts of the plywood base

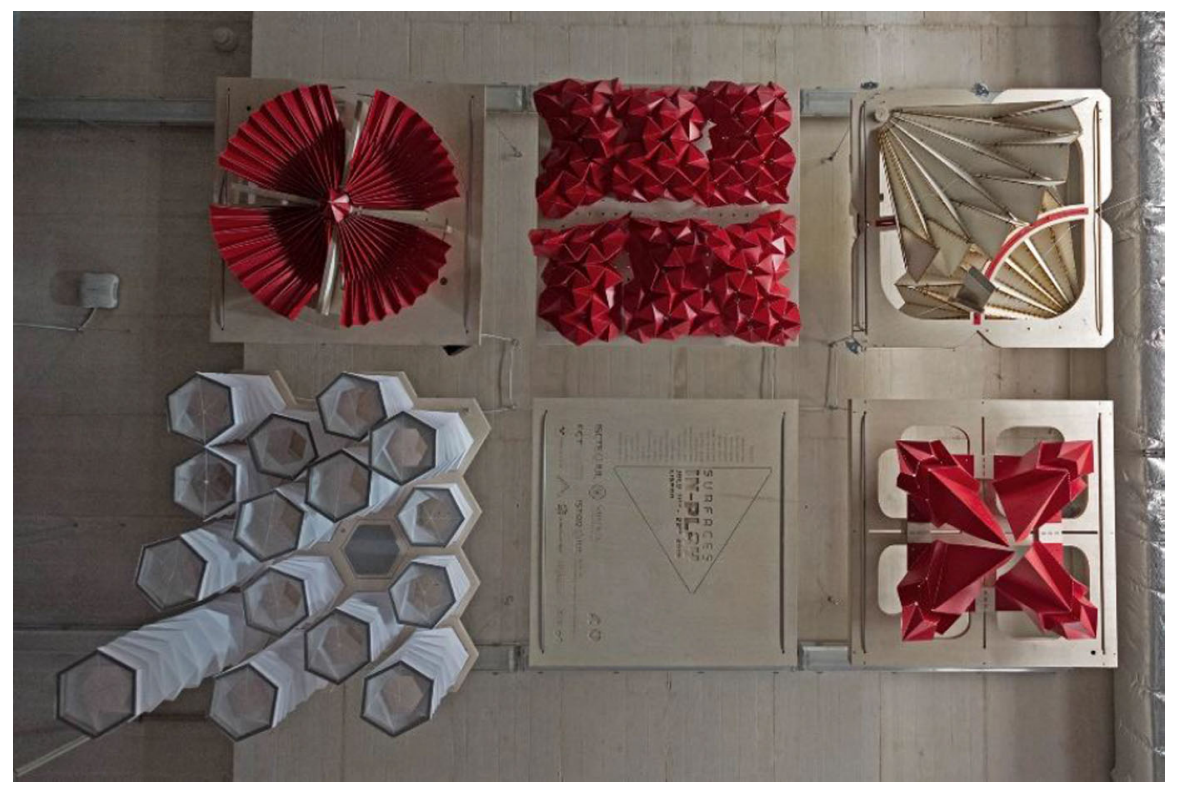

Fig. 4 In-play's final prototypes. Source: Filipa Osório 


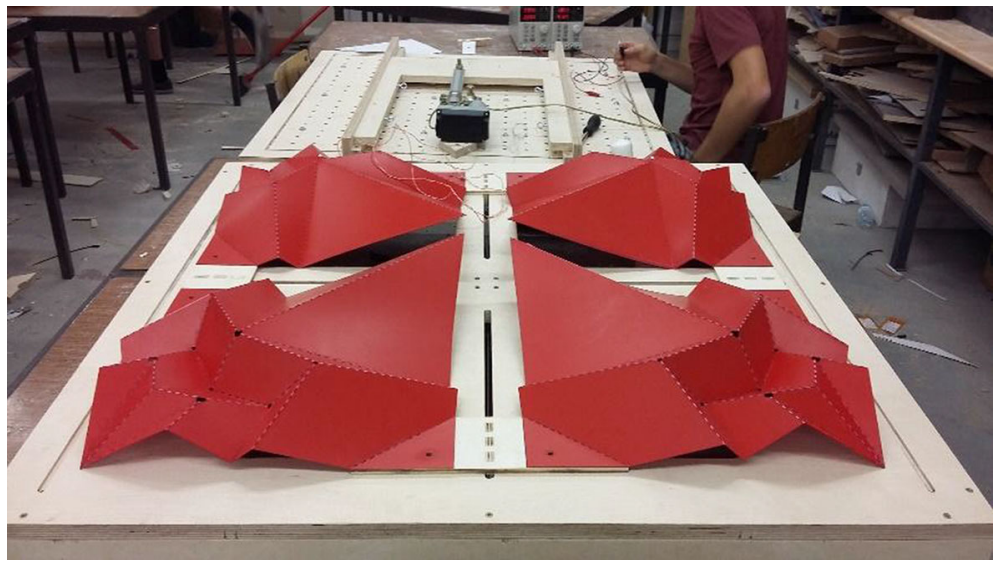

Fig. 5 Group A prototype. Source: Filipa Osório

to place the surfaces; that is, one was suspended while the other was supported by the base. Through this design Group $\mathrm{C}$ explored the interaction between the object and the user and worked the most with the arduino possibilities.

\section{Conclusion}

The Architecture in-Play Conference and Surfaces in-Play Summer School design studio collectively provided an opportunity to build a global perspective in kinetic design studies and contribute to new knowledge about transformable architectural solutions with deployable rigid origami surfaces, by structuring knowledge about kinetic systems, deployable structures and rigid origami geometry.

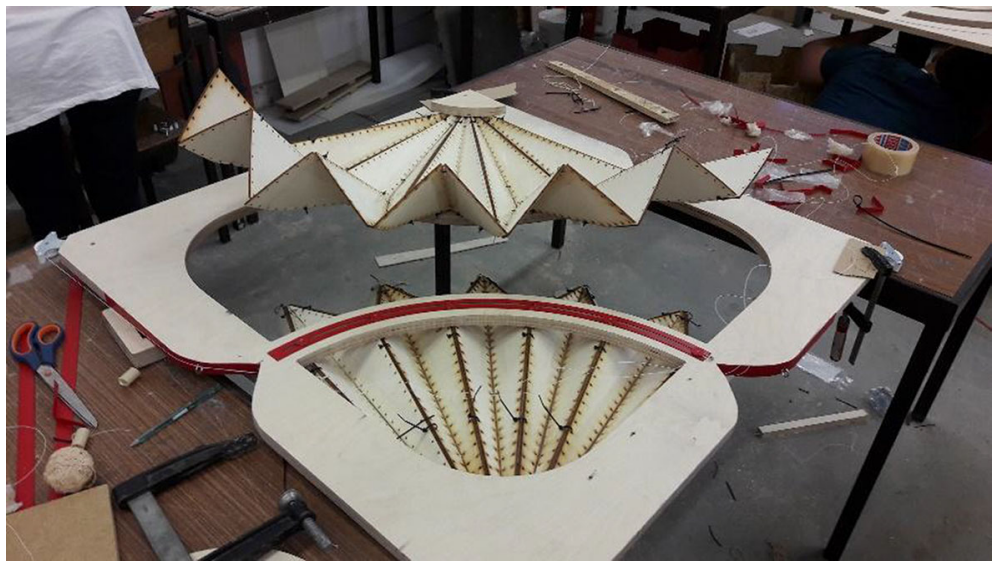

Fig. 6 Group C prototype. Source: Filipa Osório 
The proposed comprehensive work method allowed the design studio participants to follow every step of the architectural process. This was of great importance to test, in a practical way, the work method, the proposed digital simulation tools, rigid origami geometry, materials, kinetic and mechanic systems and digital fabrication. In this design process the architect was placed as a constant presence in every stage, and had the tools for decision making with awareness and consideration in respect of those same stages and the ways they influence each other and the final design and construction. The groups were free to create their own structure and crease pattern, and learned how to solve unexpected problems at every stage of the process. The five origami foldable surface-cover prototypes revealed that the participants learned from the proposed digital workflow and were able to perform every step, from the beginning to the end, in an independent way and within the available time. The results demonstrated that computational design requires greater sensitivity to innovation and this must encompass the school culture.

Considering the relevance of kinetic design in architecture at a global scale, and its increasing prevalence in the last decade, it is still difficult to anticipate its impact on the built environment. The benefits of interactive architectural applications are found in learning to articulate the dynamic possibilities of built form and in learning how an architectural environment can be empowered, and this goes beyond a simple ability to adapt. The evolution of AI (artificial intelligence), in particular, is economically feasible and could be the possible answer. Cognition emerges as embodied interaction, and instead of predefining the behaviour, AI theories and techniques show this behaviour can be learned by recording real-world phenomena. In this way architecture can be seen as a "living organism".

Acknowledgements The authors would like to acknowledge the event sponsors: FCT— Foundation for Science and Technology, Luso American Development Foundation, Araújo \& Lino, Leroy Merlin, Sumol + Compal, Copianço cópias; and Scholarships sponsors: ISTAR-IUL (R\&D unit) and ISTA.

The authors would also like to thank the workshop participants (Daniela Nóbrega, Denton Fredrickson, Federico Galizi, Inês Caetano, Ioanna Mitropoulou, Jan Broux, Maia Zheliazkova, Maria Bezzone, Pedro Januário, Ronaldo Barbosa) and the contribution of the other teachers Andrea Casale and Michele Calvano; and tutors: João Sousa, João Ventura, Maria João Oliveira, Maurizio Giodice, Susana Neves, and Vasco Craveiro Costa.

Funding Filipa Osório's research is funded by an FCT scholarship with reference SFRH/BD/100818/ 2014.

\section{References}

Bier, Henriette and Terry Knight. 2010. Digitally-Driven Architecture. Footprint. Delft School of Design Journal 6:1-4.

Casale, Andrea and Graziano M. Valenti. 2012. Architettura delle Superfici Piegate, le Geometrie che Muovonogli Origami, Nuovi quaderni di Applicazioni della Geometria Descrittiva. Edizioni Kappa.

Casale, Andrea, Graziano M. Valenti and Michele Calvano. 2016. From Origami to Folded Surfaces. Representing Moving Forms. The 17th International Conference on Geometry and Graphics:0-11. 
Cowen, Tyler. 2013. The Average is Over. New York: Dutton.

Daly, Ian. 2011. Data Cycle: Behind MIT's SENSEable Cities Lab. Wired Magazine April 2011.

Demaine, Erik D., Martin L. Demaine, Vi Hart, Gregory Price, and Tomohiro Tachi. 2011. (Non)existence of Pleated Folds: How Paper Folds Between Creases. Graphs and Combinatorics 27 (3):341-351.

Eastman, Charles 1971. Adaptive-Conditional Architecture. Design Participation: Proceedings of Design Research Society's Conference, Manchester, September 1971:51-57.

El-Zanfaly, Dina E. 2011. Active Shapes: Introducing Guidelines for Designing Kinetic Architectural Structures. Boston: MIT.

Fox, Michael. 2016a. Catalyst Design. Architecture in-Play Proceedings:1-5.

Fox, Michael (ed). 2016b. Interactive Architecture: Adaptive World. New York: Princeton Architectural Press.

Fox, Michael and Catherine Hu. 2005. Starting from the Micro: A Pedagogical Approach to Designing Interactive Architecture. Conference of the Association for Computer Aided Design in Architecture: 78-93.

Fox, Michael and Miles Kemp. 2009. Interactive Architecture. New York: Princeton Architectural Press. Frazer, John. 1995. An Evolutionary Architecture. London: Architectural Association Publications.

Glynn, Ruairi. 2016. Machine Life. Architecture in-Play Proceedings:60-68.

Goulthorpe, Mark. 2008. The Possibility of (an) Architecture: Collected Essays by Mark Goulthorpe, dECOi Architects. New York:Routledge.

Iwamoto, Lisa. 2009. Digital Fabrications. Architectural and Material Techniques. New York: Princeton Architectural Press.

Jackson, Paul. 2011. Folding Techniques for Designers: From Sheet to Form. London: Laurence King Publishing.

Jackson, Paul. 2016. Folding as a Language of Design. Architecture in-Play Proceedings:186-194.

Kolarevic, Branko. (ed). 2003. Architecture in the Digital Age. Design and Manufacturing. New York: Spon Press.

Kolarevic Branco. and Vera Parlac (ed). 2015. Building Dynamics: Exploring Architecture of Change. Abingdon: Routledge.

Kronenberg, Robert, Joseph Lim, and Wong Y Chii. 2003. Transportable Environments 2. New York: Spoon Press.

Lang, Robert. 2010. Origami and Geometric Constructions. http://whitemyth.com/sites/default/files/ downloads/Origami/Origami\%20Theory/Robert\%20J.\%20Lang\%20-\%20Origami\% 20Constructions.pdf

Lynn, Greg. (ed.). 1993. Folding in Architecture. Architectural Design Profile 102.

Marbel, Scott. 2012. Digital Workflows in Architecture. Design-Assembly-Industry. Basel: Birkhauser.

Megahed, Naglaa. A. 2017. Understanding Kinetic Architecture: Typology, Classification, and Design Strategy. Architectural Engineering and Design Management 13:130-146.

Moloney, Jules. 2011. Designing Kinetics for Architectural Façades - State Change. New York: Routledge.

Negroponte, Nicholas. 1995. Being Digital. New York: Alfred A. Knopf.

Osório, Filipa, Alexandra Paio, Sancho Oliveira, 2017a. Kinetic Origami Surfaces. From Simulation to Fabrication. Future Trajectories of Computation in Design. 17th International Conference, CAAD Futures: 229-248.

Osório, Filipa, Alexandra Paio, Sancho Oliveira, Andrea Casale, Graziano M. Valenti, and Michele Calvano. 2017b. Foldable Responsive Surfaces. Two Design Studios with a Comprehensive Workflow. Proceedings eCAADe 35:355-362.

Osório, Filipa, Alexandra Paio, Sancho Oliveira. 2017c. Origami Tesselations: Folding Algorithms, from Local to Global. Geometrias'17 Proceedings.

Pask, Gordon. 1969. Architectural Relevance of Cybernetics. Architectural Design:494-496.

Peters, Brady and Terri Peters. 2013. Inside SmartGeometry. Expanding the Architectural Possibilities of Computational Design. John Wiley \& Sons Ltd.

Rifkin. Jeremy. 2011. Third Industrial Revolution. Palgrave Macmillan.

Rivas-Adrover, Esther R. 2015. Deployable Structures. London: Laurence King Publishing Ltd.

Sadler, Simon. 2005. Archigram Architecture Without Architecture. Cambridge: MIT Press.

Saggio, Antonino. 2013. The IT Revolution in Architecture Thoughts on a Paradigm Shift. New York: ITools/Lulu.com. 
Schenk, Mark and Simon Guest. 2011. Origami Folding: A Structural Engineering Approach. Origami 5 Fifth International Meeting of Origami Science, Mathematics, and Education. Boca Raton: CRC Press.

Tachi, Tomohiro. 2011. Rigid-Foldable Thick Origami. Origami 5 - Fifth International Meeting of Origami Science, Mathematics, and Education. Boca Raton: CRC Press.

Tedeschi, Arturo. 2011. Parametric Architecture with Grasshopper. Brienza: Le Penseur Publisher.

Tedeschi, Arturo. 2014. AAD Algorithms-Aided Design. Parametric Strategies Using Grasshopper. Brienza: Le Penseur Publisher.

Tedeschi, Arturo. 2016. Hyper-Meritocracy and Architecture. Architecture in-Play Proceedings:122-125.

Valenti, Graziano M., Milena Fantozzi, and Alessio Petecchia. 2016. The Form of the Design: Digital Processing a Priori and a Posteriori. 3D Modeling \& Bim Applications and Possible Future Developments:553-566.

Walter, William G. 1950. An Electro-Mechanical “Animal”. Discovery 11:90-93.

Weiser, Mark. 1991. The Computer for the 21st Century. Computers and Networks: How to Work, Play and Thrive in Cyberspace 265(3):94-105.

Wiener, Norbert. 1948. Cybernetics: Or Control and Communication in the Animal and the Machine. Paris: Hermann and Camb.

Zuk, William and Roger H. Clark. 1970. Kinetic Architecture. New York: Van Nostrand Reinhold.

\begin{abstract}
Alexandra Paio is Assistant Professor in the Department of Architecture and Urbanism at ISCTE-IUL, where she is also Director of the PhD Program in Architecture of Contemporary Metropolitan Territories and Vice-Dean of the Department of Architecture and Urbanism. She is Director and researcher of VitruviusFabLab-IUL, researcher at ISTAR-IUL (R\&D unit at ISCTE-IUL) and Dinâmia'CET (R\&D unit at ISCTE-IUL). Her main research interests are Computational Design, Digital tools and processes to support the creative design, Interactive architecture, Shape Grammars, and Digital Fabrication.
\end{abstract}

Filipa Osório graduated in architecture (2006) at Faculdade de Ciências e Tecnologia da Universidade de Coimbra having made one academic year at Università degli Studi di Roma - La Sapienza, under the Socrates-Erasmus program. She started her $\mathrm{PhD}$ research at ISCTE-IUL, ISTAR-IUL with the theme Kinetic Folded Surfaces for Big Spans with a scholarship from Fundação para a Ciência e Tecnologia with reference SFRH/BD/100818/2014. In addition to the In-Play Conferences and Summer School, she was also a tutor at Summer Schools Responsive Surfaces in Rome (2015, 2017).

Sancho Moura Oliveira is an assistant professor and researcher at Lisbon University Institute (ISCTEIUL) and Institute of Telecommunications. He has a PhD and Master in Physics from Universidade de Lisboa and he is a graduate of Computer Engineering from Instituto Superior Técnico. His main scientific research areas are complex distributed systems and evolutionary computation. His research focuses on autonomous robots, multirobot systems, swarm intelligence, evolutionary computation, communication in large-scale systems, complex systems and high performance computing.

Graziano Mario Valenti is a researcher and lecturer in the Dipartimento di Storia Disegno e Restauro dell' Architettura of the Università di Roma "La Sapienza", where he also teaches courses in the Industrial Design and Science of Architecture degree programs. The main object of his research is the definition and the representation of a dynamic and integrated model containing an articulate and complex aggregate of information.

Nuno Guimarães graduated in EEC at Instituto Superior Técnico. He is Full Professor at ISCTE-IUL, Portugal. He became Full Professor at the Faculty of Sciences of the University of Lisbon (FCUL) in 2001, where he was Dean from 2004 to 2009. He was also Invited Professor at the Technische Universität Berlin (2010). He is a senior member of ISTAR (R\&D unit), and was a consultant for AT\&T Bell Labs, Murray Hill, NJ, USA (1989/1991). 